\title{
Metal Nanoparticle Containing Nanocomposites of Drug Substances and Their Potential Biomedical Applications
}

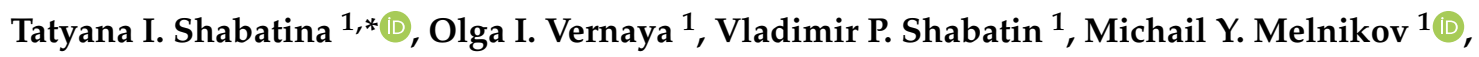 \\ Alexandr M. Semenov ${ }^{2}$ and Vladimir I. Lozinsky ${ }^{3}$ \\ 1 Department of Chemistry, Moscow State University, Moscow 119991, Russia; olga_vernaya@mail.ru (O.I.V.); \\ vovapsh@rambler.ru (V.P.S.); melnikov46@mail.ru (M.Y.M.) \\ 2 Department of Biology, Moscow State University, Moscow 119991, Russia; amsemenov@list.ru \\ 3 A. N. Nesmeyanov Institute of Organoelement Compound, Russian Academy of Sciences, \\ Moscow 119991, Russia; loz@ineos.ac.ru \\ * Correspondence: tatyanashabatina@yandex.ru; Tel.: +7-495-939-5442
}

Received: 21 November 2019; Accepted: 20 December 2019; Published: 24 December 2019

Featured Application: The resulting systems are promising for drug delivery and controlled release of bioactive drug molecules.

\begin{abstract}
New hybrid nanosystems containing the antibacterial substances dioxidine or gentamicin sulfate with bioactive metal $(\mathrm{Ag}, \mathrm{Cu})$ nanoparticles have been obtained by a cryogenic freeze-drying method and incorporate further the nanocomposites thus obtained into the cryogenically structured biopolymeric matrices based on gelatin, calcium alginate, and chitosan. FTIR, UV-visible, and NMR spectroscopy, TEM and SEM microscopy data show that the resulting systems consist of wide-porous polymer sponges (pore diameters, $10-200 \mu \mathrm{m}$ ) that contain antibacterial drugs and silver $(2-30 \mathrm{~nm})$ or copper $(1-5 \mathrm{~nm})$ nanoparticles. The investigation showed that these systems ensure a gradual release of dioxidine (from $40 \mathrm{~min}$ up to 3 days), depending on the nature of the matrix and its microstructure. The higher activity of hybrid composites based on nanometals and dioxidine or incorporated into cryostructured biopolymer matrices against the bacterial strains of Escherichia coli 52, Staphylococcus aureus 144 is demonstrated as compared to the individual components in the same matrices.
\end{abstract}

Keywords: cryochemical modification; hybrid nanoforms; antibacterial drugs; dioxidine; gentamicin sulfate; silver nanoparticles; copper nanoparticles; cryostructured biopolymeric sponges; gelatin; calcium alginate; chitosan

\section{Introduction}

The success of modern pharmacology is associated not only with production of new drug substances and their pharmaceutical compositions, but also with the development of new forms, and especially nanoforms, of already existing drugs. The efficiency of drug substances could be improved by the elaboration of new hybrid compositions containing known drug preparations and nanoscale biologically active inorganic particles [1-3]. The hybrid nanoforms capable of the controlled release of drug substances, including forms of prolonged action whose drug release takes longer time in comparison with the individual drugs, and their pharmaceutical compositions possess promising therapeutic applications [4-7]. The use of drug forms with controlled release and prolonged action led to a decrease in the peak concentration of the drug substance in the human body and exclude temporary fluctuations in the concentration of the active substance in the blood and tissues, which are periodically repeated by the use of traditional medical preparations. Such drug forms can be created by 
the incorporation of a pharmacologically active component into a biopolymeric matrix, which provides gradual release of the drug and prolonged maintenance of the desired concentration of the active drug in the body or locally in a target organ. Systems based on polysaccharides (starch, cellulose, chitosan, hyaluronic acid, calcium alginate) and proteins (such as albumin, gelatin, transferrin, lactoferrin, silk fibroin, collagen, and $\beta$-casein) are used as carriers for drugs [8]. Biopolymers are preliminarily modified, fixing their dimensions and inner spatial network to optimize their biocompatibility and ability to control release of the bioactive compounds, which are incorporated into the matrix before their use. Biopolymers are used as nano- and microparticles (for oral and intravenous insertion) and bulky hydrogel matrices (cryogels if the matrix is formed at low temperatures) with controlled drug release for local application $[9,10]$. The systems based on chitosan, gelatin, and calcium alginate could be also used as possible biopolymer depots for drug substances with their elongated and controlled release [11-14].

The goal of this work was to synthesize new hybrid nanocomposites based on the antibacterial substance dioxidine and gentamicin sulfate, each combined with the bioactive metal nanoparticles (silver or copper), and to incorporate the obtained nanocomposites into highly porous cryostructured polymer matrices of calcium alginate, gelatin, and chitosan capable for prolonged drug release. The antibacterial activity of these hybrid antibacterial nanoforms was evaluated against bacterial strains of the Escherichia coli 52, Staphylococcus aureus 144.

\section{Materials}

Dioxidine and gentamicin sulfate (Mir Pharma, Russia) corresponding to the pharmacopeia articles 42-2308-97 and 42-2628-00, colloidal silver of KND brand (TU 9154 024741070962008, SK, Russia), copper II chloride, and hydrazine hydrate of analytical grade were used without additional purification (RusChim, Russia). Copper nanoparticles were obtained by reducing an aqueous solution of copper chloride by hydrazine hydrate [15].

Fine powder of an antibacterial drug and its hybrid composites with silver (Ag/dioxidine and $\mathrm{Ag} / \mathrm{gentamicin}$ sulfate) or copper $(\mathrm{Cu} /$ dioxidine and $\mathrm{Cu} /$ gentamicin sulfate) nanoparticles were prepared by spraying the aqueous solution containing antibacterial drug and metallic nanoparticles ( $1 \mathrm{wt} . \%$ of dioxidine, $0.005 \mathrm{wt} . \%$ of $\mathrm{Ag}$, or $0.02 \mathrm{wt} . \%$ of $\mathrm{Cu}$ ) using an air stream atomizer into the liquid nitrogen; then, the frozen solutions were subjected to the procedure of freeze drying for $24 \mathrm{~h}[16,17]$.

The low temperature synthesis cryogenically structured biopolymeric matrices of calcium alginate, chitosan, and gelatin, was performed according to the earlier published procedures [18-20]. These materials in a dry state are, according to the SEM microphotographs, the wide-pore sponges with pore diameters of 10-100 microns.

The hybrid systems "Ag/antibacterial drug/biopolymer matrix" and "Cu/antibacterial drug/biopolymer matrix" were prepared according to the following scheme: Spongy disks of the cryostructed polymer matrices were immersed for $30 \mathrm{~min}$ in an aqueous solutions of drugs and metallic nanoparticles ( $1 \mathrm{wt} . \%$ of dioxidine or gentamicin sulfate, $0.02 \mathrm{wt} . \%$ of $\mathrm{Ag}$ or $\mathrm{Cu}$ ); then, the disks were taken out from the solution, frozen at $-30{ }^{\circ} \mathrm{C}$, and subjected to the freeze drying procedure during $24 \mathrm{~h}$. The samples based on calcium alginate (Ag/antibacterial drug/Ca-alginate and $\mathrm{Cu} /$ antibacterial drug/Ca-alginate) contained $14.3 \mathrm{wt} . \%$ of drug and $0.9 \mathrm{wt} . \%$ of metal, the composites based on gelatin (Ag/antibacterial drug/gelatin and $\mathrm{Cu} /$ antibacterial drug/gelatin) contained $11.5 \mathrm{wt} . \%$ of drug and $0.4 \mathrm{wt} . \%$ of metal, and the composites based on chitosan (Ag/antibacterial drug/chitosan and $\mathrm{Cu} /$ antibacterial drug/chitosan) contained $4.8 \mathrm{wt} . \%$ of drug and $1.5 \mathrm{wt} . \%$ of metal.

\section{Methods}

X-ray phase analysis of the samples obtained was performed at Rigaku D/MAX-2500 X-ray diffractometer (Rigaku, Japan) using $\mathrm{Cu} / \mathrm{K} \alpha$ irradiation line $(\lambda=1.54056 \AA)$. 
The FTIR spectra of the samples were obtained in the range of $4000-400 \mathrm{~cm}^{-1}$ using Bruker Tensor II FTIR-spectrometer (Germany) with reflection platinum unit. The FTIR spectra of powdered samples were recorded in diffuse reflection mode.

The UV-VIS absorbance spectra of the aqueous solutions were recorded at Jasco V-770 spectrophotometer (Jasco, Japan) in the range of 300-500 nm.

The kinetic curves for the release of dioxidine from the composite nanoforms obtained in the distilled water were measured spectrophotometrically at wavelength $\lambda=375 \mathrm{~nm}$ using Jasco V-770 spectrophotometer (Jasco, Japan). The kinetics of gentamicin sulfate release were monitored by measuring of the electrical conductivity of the drug solutions using a Mettler Toledo Conductometer (Switzerland) with LE703 electrodes. Each sample was measured 3 times independently. The standard deviation of the experimental data is shown in Figure 4 for all experimental curves.

Metal concentration inside the polymeric matrices of hybrid antibacterial nanoforms was determined by atomic absorption method at Spectrometer i-CE 3000 (Thermo Fisher Scientific, USA).

The ${ }^{1} \mathrm{H}-\mathrm{NMR}$ (nuclear magnetic resonance) spectra were recorded in deuterated water solutions $\left(\mathrm{D}_{2} \mathrm{O}\right)$ using a high-resolution NMR spectrometer VXR-400 (Varian, USA).

The microstructure of the samples was studied using the transmission electron microscopy (TEM) using electron microscope LEO 912 AB Omega (ZEISS, Germany) at $\times 400-\times 500000$ magnifications and using scanning electron microscope (SEM) Phenom (FEI Company, Germany) at $\times 40-\times 4000$ magnifications.

Specific surface area $\left(\mathrm{S}_{\mathrm{sp}}\right)$ of the nanocomposites was studied by the method of thermal argon desorption using gas-chromatograph Chrom-5 (Czech Republic). The resorbed gases were removed from the surface of the samples using the vacuum setup. Mean dimensions particles were calculated as a $=6 /\left(\varrho S_{\text {sp }}\right)$, where $\varrho$ is the density of drug.

The evaluation of the antibacterial activity of the samples was carried out by the disk-diffusion method using the filter paper disks or sponges of cryogenically structured biopolymeric samples (4 $\mathrm{mm}$ in diameter and $2 \mathrm{~mm}$ in height). Bacterial strains of E. coli 52 and S. aureus 144 were used from the collection the Microbiology Department, Biology Faculty of M.V. Lomonosov Moscow State University. The experiments were carried out in standard Petri dishes containing $20 \mathrm{~mL}$ of agar nutrient medium dried during the day (thickness of the medium layer was of $4 \mathrm{~mm}$ ). Measurements of inhibition zones (IZ) for bacterial strains growth of the tested cultures were carried out after $24 \mathrm{~h}$ of incubation. Statistically reliable results were obtained by a nine-fold repetition of the measurements for each series of samples.

\section{Results}

To ascertain the composition and structure of the samples, they were subjected to physicochemical analysis. Dioxidine was modified at the first stage. The drug substance particles were micronized, and silver or copper nanoparticles were incorporated into the dioxidine particles during cryogenic synthesis procedure. FTIR spectra of the systems obtained were similar to cryomodified form of dioxidine obtained via cryogenic freeze drying method $[16,21,22]$. The band corresponding to the vibrations of quinoxaline ring was at $1510 \mathrm{~cm}^{-1}$; the bands corresponding to the vibrations of the $\mathrm{C}-\mathrm{H}$ bonds of the benzene rings were registered at 975,1130 , and $1160 \mathrm{~cm}^{-1}$; the band of $\mathrm{C}-\mathrm{O}-\mathrm{H}$ vibrations was observed at $1288 \mathrm{~cm}^{-1}$.

X-ray diffraction patterns and the set of interplanar spacings $(\mathrm{d}, \AA)$ and their intensities $\left(\mathrm{I}_{\text {rel }}, \%\right)$ corresponded to the cryomodified form of dioxidine [21,22] (d, $\AA, \mathrm{I}_{\text {rel }}, \%: 8.740,100.0 ; 8.026,94.2 ; 6.899$, $57.8 ; 6.288,50.9 ; 5.978,43.4 ; 3.358,99.3 ; 3.304,67.6)$. The absence of peaks corresponding to silver or copper in the X-ray diffraction of patterns was due to low metal content and the nanoscale size of their particles in each sample.

The ${ }^{1} \mathrm{HNMR}$ spectra of the formed hybrid systems (in $\left.\mathrm{D}_{2} \mathrm{O}\right) \delta: 4.94-5.22(\mathrm{~m}, 4 \mathrm{H}, 2 * \mathrm{CH} 2), 7.85-8.05$ $(\mathrm{m}, 2 \mathrm{H}, \mathrm{H} \mathrm{Ar})$, and $8.37-8.52(\mathrm{~m}, 2 \mathrm{H}, \mathrm{H} \mathrm{Ar})$ were corresponded to dioxidine.

The UV-visible spectra of aqueous solutions of $\mathrm{Ag} /$ dioxidine and $\mathrm{Cu}$ /dioxidine composites also were corresponded to dioxidine. An intense absorption band at $250 \mathrm{~nm}$, attributed to the $\pi \rightarrow \pi^{*}$ electron transition of the carbon atoms of the aromatic system, was observed in UV spectra, along with a band at $375 \mathrm{~nm}$ characterized by low intensity and attributed to the $\mathrm{n} \rightarrow \pi^{*}$ transition. The absence 
of absorbance bands corresponding to the surface plasmonic resonance (SPR) of silver or copper nanoparticles was due to the low content of silver or copper nanoparticles in each sample.

According to the TEM data, obtained $\mathrm{Ag} /$ dioxidine and $\mathrm{Cu}$ /dioxidine nanocomposites (Figure 1) were composed of organic particles $(50-350 \mathrm{~nm})$ containing nanoscale particles of silver $(2-30 \mathrm{~nm})$ or copper $(1-10 \mathrm{~nm})$. The specific surface of the $\mathrm{Ag} /$ dioxidine composites was $31 \mathrm{~m}^{2} / \mathrm{g}$ (average particle size, $130 \mathrm{~nm}$ ), and the specific surface of the $\mathrm{Cu} /$ dioxidine composite was $24 \mathrm{~m}^{2} / \mathrm{g}$ (average particle size, $166 \mathrm{~nm}$ ). The specific surface of the $\mathrm{Ag} /$ gentamicin sulfate was $32 \mathrm{~m}^{2} / \mathrm{g}$ (average particle size, $144 \mathrm{~nm}$ ), and the specific surface of the $\mathrm{Cu} /$ gentamicin sulfate was $31 \mathrm{~m}^{2} / \mathrm{g}$ (average particle size, $149 \mathrm{~nm}$ ). These data were in good agreement with the TEM results.

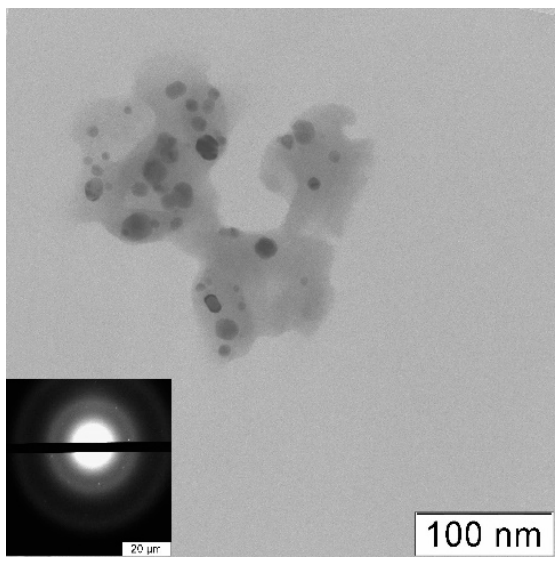

(a)

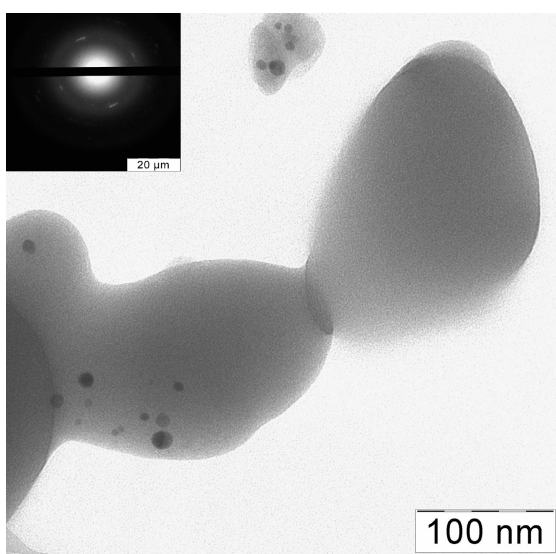

(b)

Figure 1. TEM micrographs and selected area electronic diffraction (SAED) patterns of hybrid composites of dioxidine with silver nanoparticles (a), gentamicin sulfate with copper nanoparticles (b).

The FTIR spectra of hybrid composites of gentamicin sulfate with silver and copper nanoparticles were corresponded to the FTIR spectrum of gentamicin sulfate (bands of the $\mathrm{NH}_{2-}, \mathrm{NH}_{3}$ - groups at 1520,1625 , and $3280 \mathrm{~cm}^{-1} ; \mathrm{HSO}_{4}{ }^{-}$and $\mathrm{C}-\mathrm{O}$ at $1059 \mathrm{~cm}^{-1}$; and $\mathrm{SO}_{2}$ at $607 \mathrm{~cm}^{-1}$ were characteristic for gentamicin sulfate [23]). The ${ }^{1} \mathrm{H}$ NMR spectra of hybrid composites of gentamicin sulfate with silver and copper nanoparticles, as well as the compounds released from the composite nanoforns incorporated in the biopolymer matrices, were corresponded to literature data for gentamicin sulfate [24,25].

According to TEM micrographs, the Ag/gentamicin sulfate and $\mathrm{Cu} /$ gentamicin sulfate nanocomposites consisted of organic particles (50-350 nm in size), inside of which the nanosized particles were incorporated, and their electron diffractograms were corresponded to silver or copper. The size of metal nanoparticles in the obtained systems was 2-30 nm for silver and 1-9 $\mathrm{nm}$ for copper.

The hybrid nanocomposites "Ag/antibacterial drug" or "Cu/antibacterial drug" were loaded into the cryogenically structured biopolymer wide-pore spongy matrices based on gelatin, chitosan, or Ca-alginate. The FTIR spectra of the resulting systems showed the superpositions of the vibrational bands of the hybrid nanocomposites and polymeric matrix, thus confirming the incorporation of dioxidine or gentamicin sulfate into the biopolymer matrices. The wide bands attributed to chitosan $\left(580 \mathrm{~cm}^{-1}\right)$, gelatin $\left(534 \mathrm{~cm}^{-1}\right)$, and Ca-alginate $\left(550 \mathrm{~cm}^{-1}\right)$ overlapped several narrower bands corresponding to dioxidine.

The ${ }^{1} \mathrm{HNMR}$ spectra of the substances released from the hybrid depot nanoforms in $\mathrm{D}_{2} \mathrm{O}$ were similar to ${ }^{1} \mathrm{HNMR}$ spectra of individual dioxidine or gentamicin sulfate. The UV spectra of aqueous extracts of the Ag/dioxidine/gelatin, Ag/dioxidine/chitosan, Ag/dioxidine/Ca-alginate, $\mathrm{Cu} /$ dioxidine/gelatin, $\mathrm{Cu}$ /dioxidine/chitosan, and $\mathrm{Cu} /$ dioxidine/Ca-alginate systems were corresponded to the UV-visible spectra of dioxidine.

It was shown that loading of the cryogenically structured wide-porous polymeric matrices with antibacterial drugs and metal nanoparticles did not significantly affect the pore size distribution of the biopolymeric carriers, thus suggesting that dioxidine and gentamicin sulfate were in a highly 
dispersed form in the pores of the matrices (Figure 2). Nanoparticles of silver and copper after being incorporated into such biopolymeric sponges were visible in the TEM microphotographs, and their presence was confirmed by the electron diffraction patterns of TEM. The size of metal nanoparticles in the obtained systems was 2-30 $\mathrm{nm}$ for silver and 1-10 $\mathrm{nm}$ for copper (Figure 3).


(a)
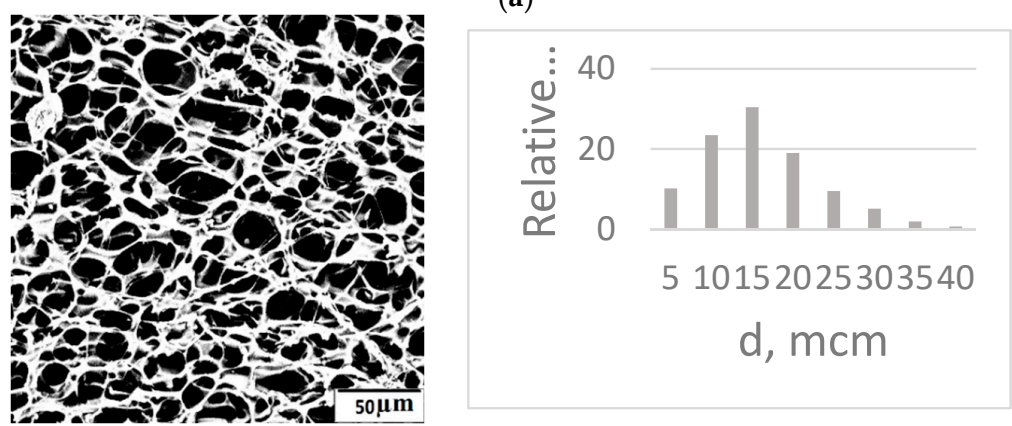

(b)
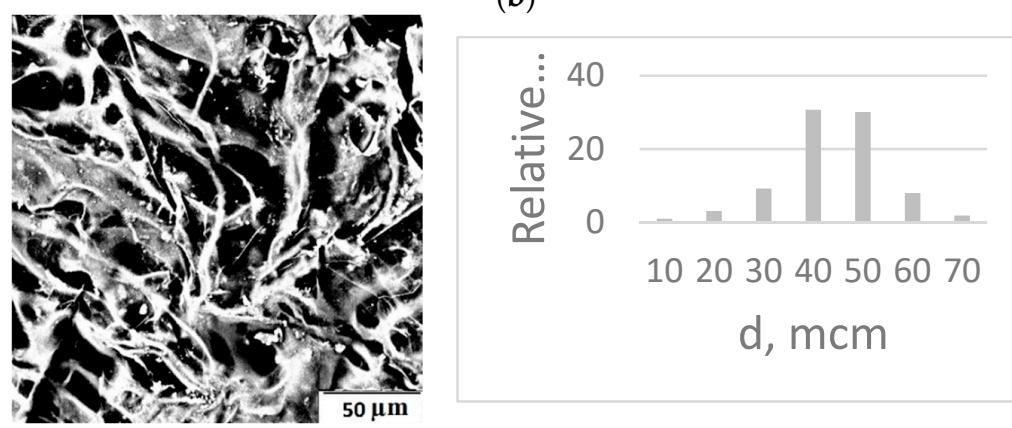

(c)

Figure 2. SEM micrographs and the pore size distribution $\mathrm{Cu} /$ gentamicin sulfate/Ca-alginate (a), $\mathrm{Ag} /$ gentamicin sulfate/gelatin (b), and $\mathrm{Cu} /$ dioxidine/chitosan (c) systems.

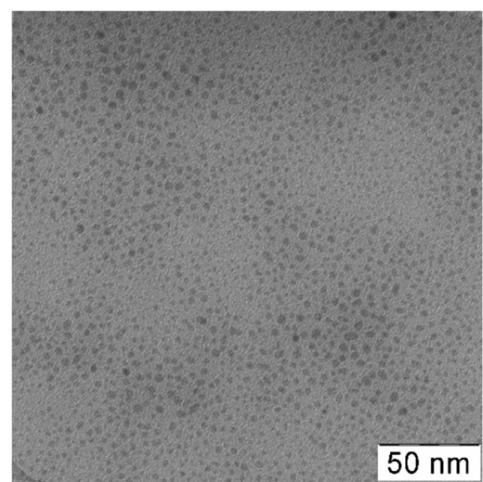

(a)

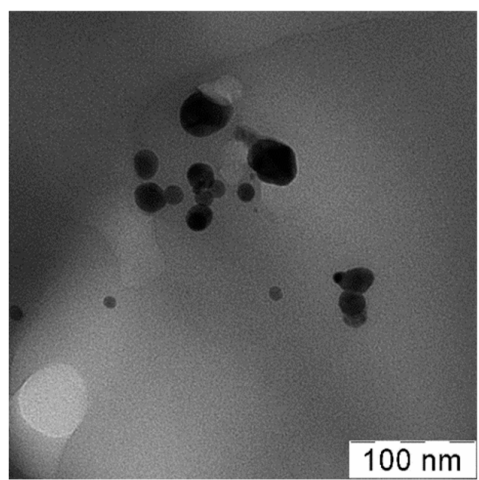

(b)

Figure 3. TEM micrographs of $\mathrm{Cu} /$ gentamicin sulfate/Ca-alginate (a), Ag/gentamicin sulfate/gelatin (b). 
Kinetic curves of the release of dioxidine and gentamicin sulfate from hybrid nanoforms obtained by cryogenic structuring of biopolymeric matrices and after their uploading by cryoformed nanocomposites of antibacterial drugs with metal $(\mathrm{Ag}$ or $\mathrm{Cu}$ ) nanoparticles are presented in (Figure 4).

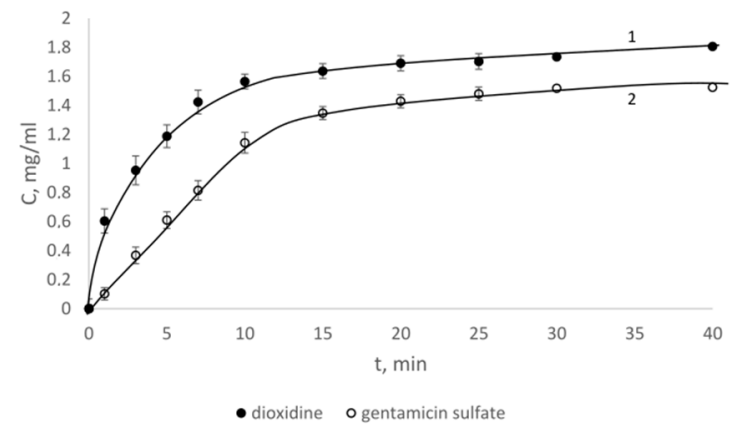

(a)

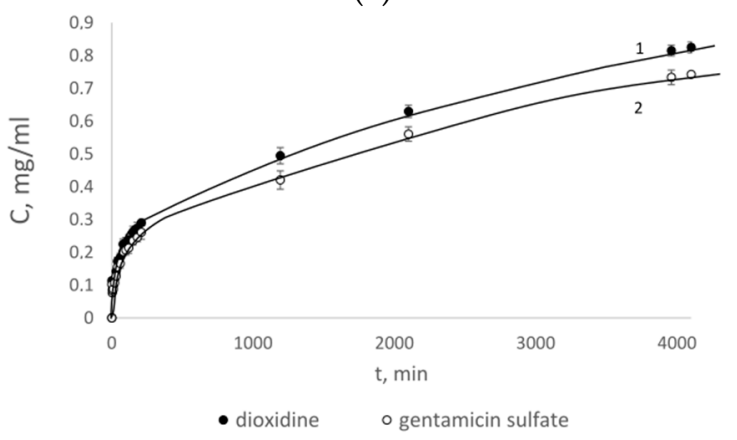

(c)

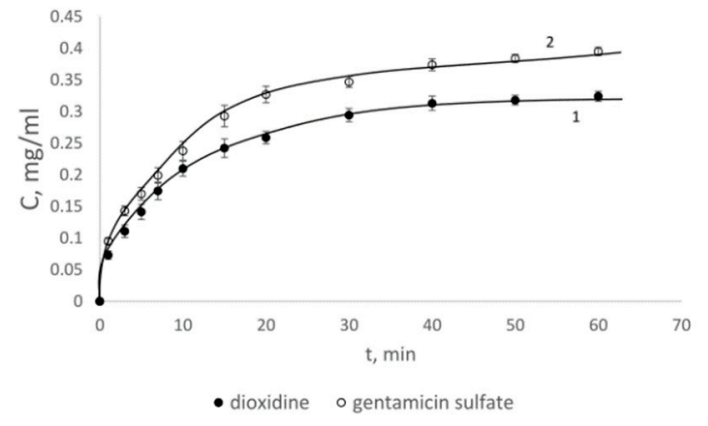

(b)

Figure 4. Kinetic curves of the release of dioxidine (1) and gentamicin sulfate (2) from the biopolymer matrices: Ca-alginate (a), gelatin (b), chitosan (c).

The release of antibacterial drugs from the Ca-alginate matrix took 40 min (Figure 4a; dioxidine, curve 1; gentamicin sulfate, curve 2), and from gelatin, $60 \mathrm{~min}$ (Figure $4 \mathrm{~b}$; dioxidine, curve 1; gentamicin sulfate; curve 2). The release of antibacterial drugs from the chitosan matrix (Figure $4 \mathrm{c}$; dioxidine, curve 1; gentamicin sulfate, curve 2) took almost three days. The data obtained indicate the presence of stronger specific interactions between the chitosan matrix and antibacterial drugs than in the case of other two matrices. However, the complete release of the loaded antibacterial drug from the chitosan matrix within three days allows us to exclude the covalent binding of drug components by the active functional centers of the chitosan biopolymer matrix. Thus, in this case, we can see a prolonged action of drug components preliminarily loaded in the nanoform with metal nanoparticles incorporated into the cryogenically structured biopolymeric sponges due to the specific intermolecular interactions. Changing the structure of the spongy carriers by varying the nature of core biopolymer and the conditions of their cryogenic formation can allow us to reduce the release rate more for the antibacterial drugs (dioxidine and gentamicin sulfate) from the hybrid nanoforms based on gelatin and Ca-alginate and to obtain a longer-lasting effect of controlled release of the drug component.

We determined the antibacterial activity of dioxidine and dioxidine-based hybrid nanosystems against E. coli 52 and S. aureus 144 bacteria. The data obtained are presented in Figures 5-7 and are given in more detailed form in Tables A1 and A2. The antibacterial activity of the hybrid composites of metal nanoparticles with dioxidine appeared to be higher than that of individual nanoparticles of metals and dioxidine in the antibacterial tests using standard disks of Ca-alginate and gelatin-based biopolymer matrices. In the case of chitosan-based biopolymer matrix: The use of hybrid nanocomposites resulted in lower antibacterial activity, relative to the individual dioxidine. Chitosan-based sponges probably differ not only in higher specific interactions of dioxidine molecules with cryostructured biopolymer carrier but also in the stronger interactions of metal nanoparticles themselves with biopolymer carrier. 
Such property of this system slowed the release of antibacterial substance dioxidine and metal ions reducing the whole antibacterial activity of the hybrid nanosystem.

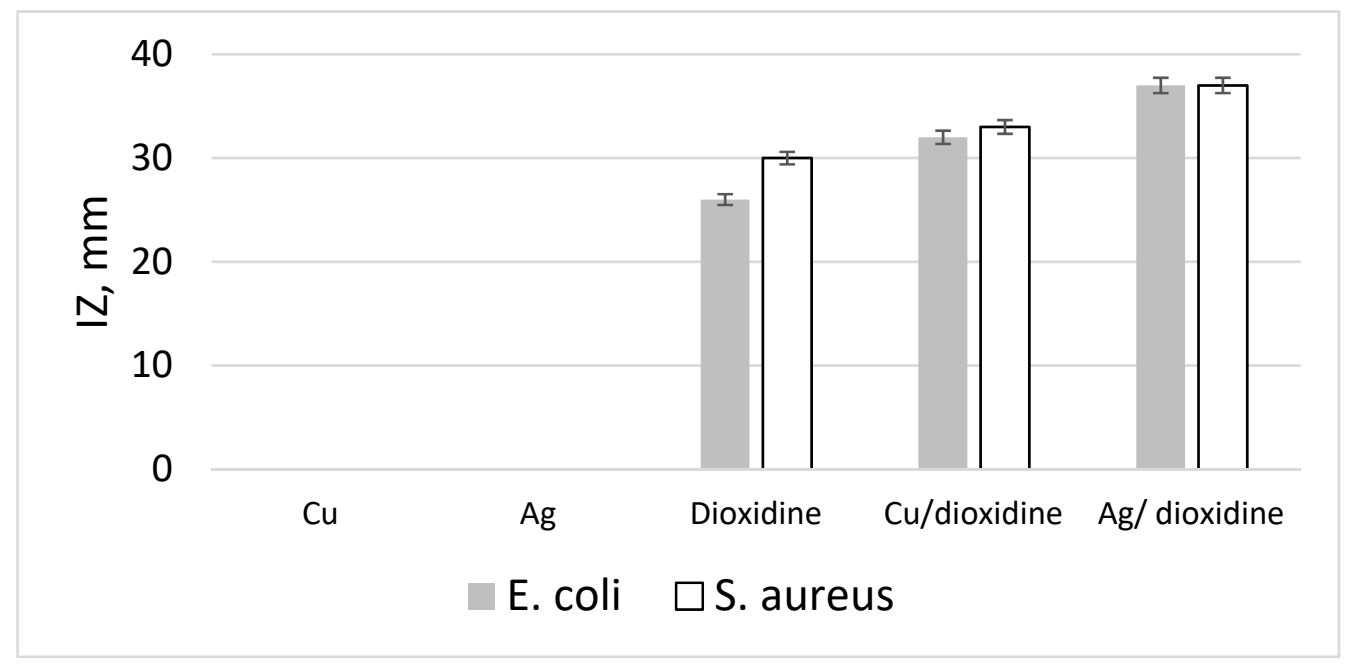

Figure 5. Inhibition zones (IZ) of bacteria strains growth for paper disks impregnated with aqueous solutions of dioxidine-based samples (dioxidine, $0.3 \mathrm{mass} \%$; Ag, $0.0015 \mathrm{mass} \%$; $\mathrm{Cu}, 0.006 \mathrm{mass} \%$ ).

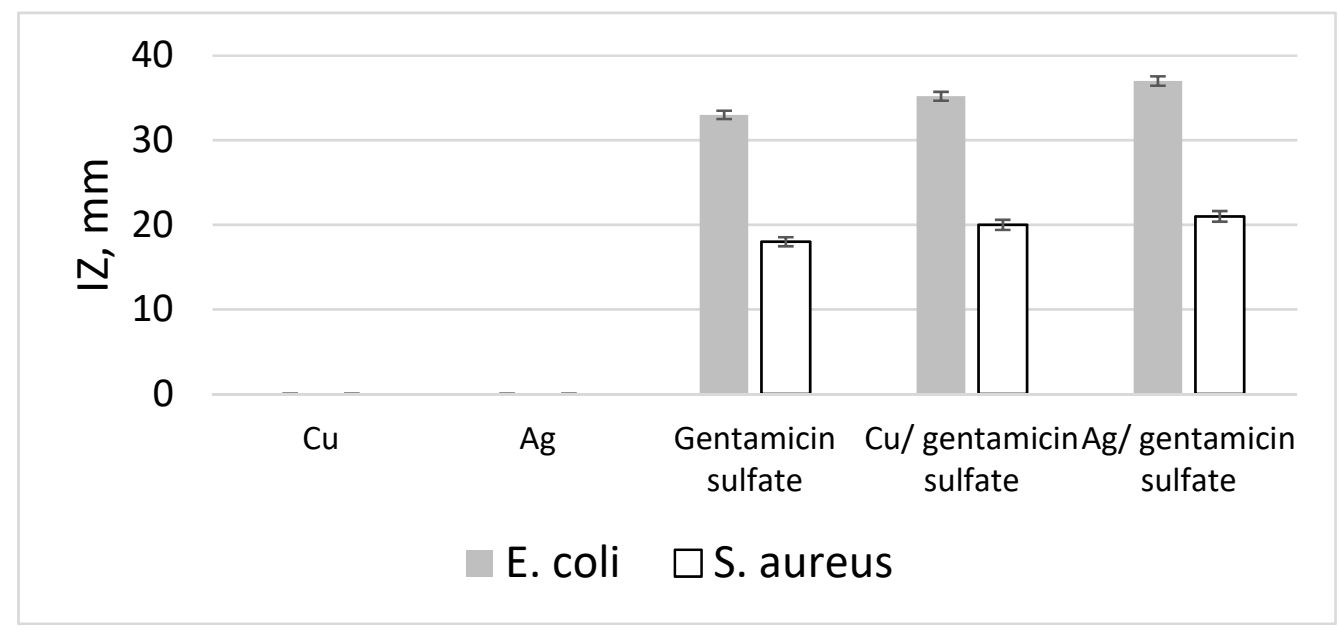

Figure 6. Inhibition zones (IZ) of bacteria strains growth for paper disks impregnated with aqueous solutions of samples based on gentamicin sulfate (gentamicin sulfate, 0.3 mass $\%$; Ag, 0.0015 mass \%; $\mathrm{Cu}, 0.006$ mass $\%)$. 




(a)

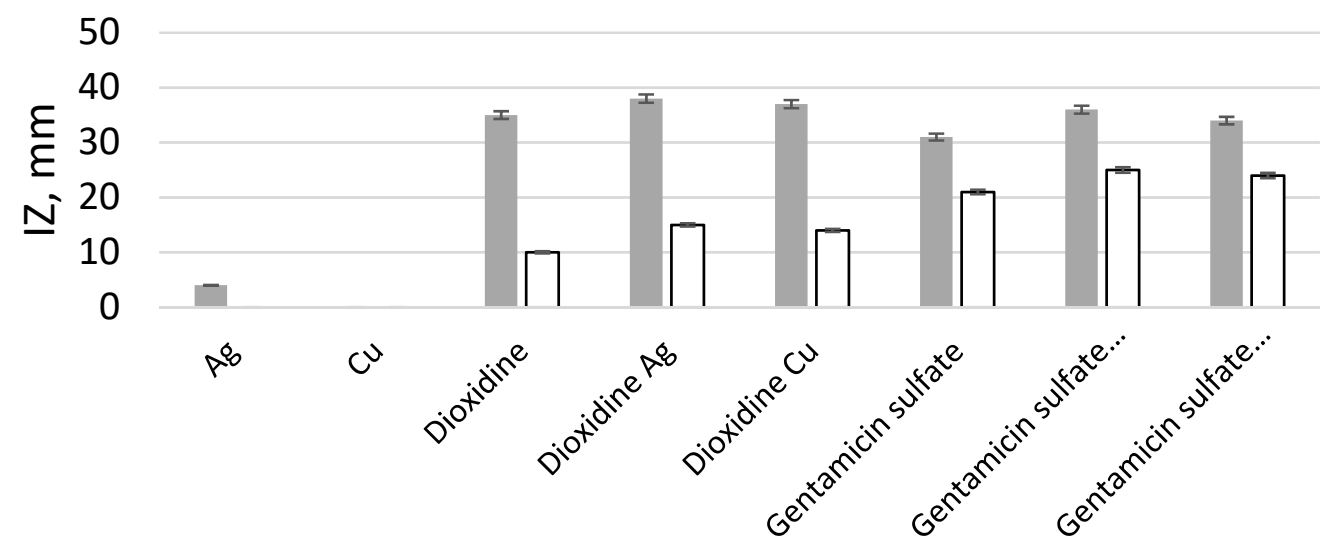

\section{E. coli $\square$ S. aureus}

(b)

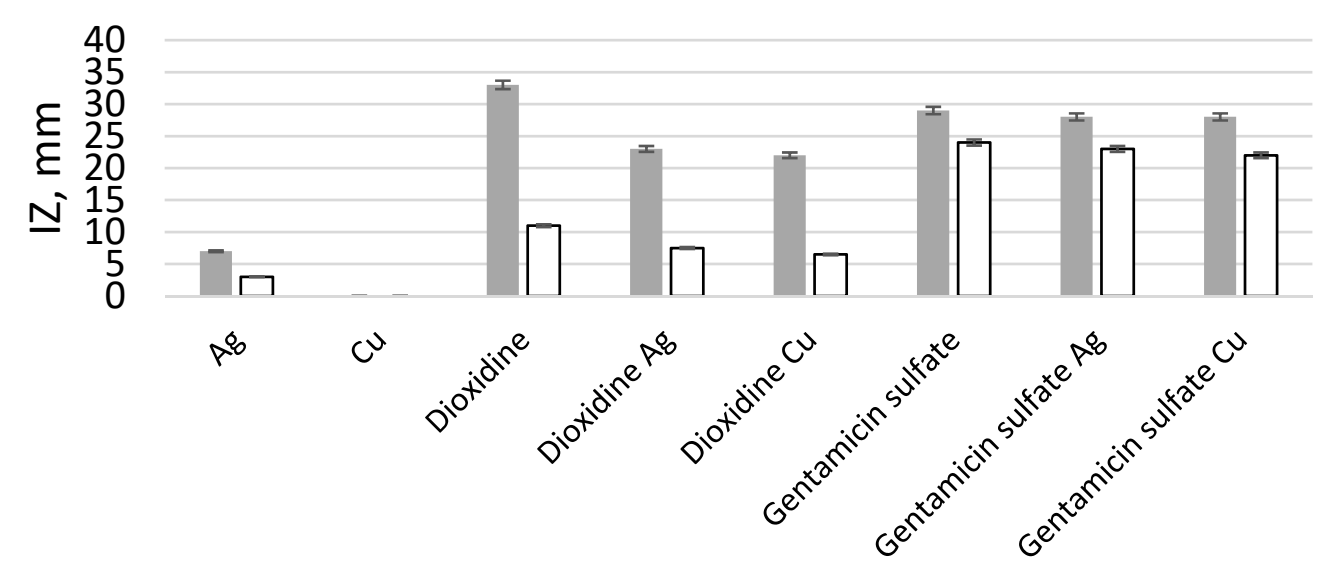

E. coli $\square$ S. aureus

(c)

Figure 7. Inhibition zones (IZ) of bacteria strains growth for biopolymer matrices (Ca-alginate (a), gelatin (b), chitosan (c)) impregnated with individual antibacterial drugs, metal nanoparticles, and their hybrid nanocomposites. 
It should be concluded that modifying gentamicin sulfate with metal nanoparticles that are active against pathogenic microorganisms also resulted in an increase of its antibacterial activity Figures 6 and 7 (Tables A2 and A3). The incorporation of hybrid composites of gentamicin sulfate with metal nanoparticles into the Ca-alginate and gelatin biopolymer matrices did not change the observed pattern, and their activity was higher in comparison to the activity of individual metal nanoparticles or individual gentamicin sulfate particles incorporated into the similar biopolymer matrices. Thus, a synergistic increase in antibacterial activity was observed for hybrid nanosystems of dioxidine and gentamicin sulfate with silver and copper nanoparticles when compared with the effect of individual components against E. coli 52 and S. aureus 144 strains.

In the case of chitosan biopolymer matrix, the antibacterial activity for hybrid nanosystems of gentamicin sulfate with metal nanoparticles was decreased. This effect was similar with the data observed for dioxidine containing chitosan-based systems and probably had a similar nature.

\section{Conclusions}

A low-temperature synthesis of hybrid composites of dioxidine and gentamicin sulfate with nanoparticles of metals (silver, copper) active against antibiotic-resistant microorganisms was carried out. Nanocomposites obtained consisted of the organic globes of dioxidine or gentamicin of 50-350 nm in size, containing silver (2-30 nm) or copper (1-10 nm) nanoparticles. The obtained hybrid systems turned out to be more active in the processes of suppressing the growth of E. coli 52 and S. aureus 144 strains than the individual components. Thus, in the case of antibacterial nanocomposites with silver and copper nanoparticles, a synergistic increase in antibacterial activity was observed when compared with the action of individual components.

The incorporation of metal-containing antibacterial drugs nanocomposites into calcium alginate and gelatin cryogenically structured polymeric matrices did not affect their microstructure and led to the observed effect of the synergistic increase in the antibacterial activity of the antibacterial drug and metal nanoparticles. It also provided a gradual release of the active drug components from the wide-porous polymeric matrices during several hours, ensured the prolonged action of the synthesized hybrid nanosystems. The biopolymeric matrix based on chitosan provided a gradual release of drug substances over almost three days.

Thus, the obtained antibacterial hybrid nanocomposites and polymeric systems including them are promising for the use as new dosage depot forms for targeted delivery and controlled release of drug components for biomedical applications. The hybrid nanosystems we obtained had a wider spectrum and higher antibacterial activity compared to the individual components. Therefore, they can be considered as promising precursors for targeted delivery and controlled release systems of drug substances in modern nanomedicine and nanopharmacology.

Author Contributions: T.I.S. and M.Y.M., writing, project administration; O.I.V. and V.P.S., hybrid nanosystems cryosynthesis and physicochemical characterization; V.I.L., biopolymer matrices synthesis; A.M.S., antibacterial activity studies. All authors have read and agreed to the published version of the manuscript.

Funding: The Russian Science Foundation, project no. 16-13-10365, financial support of this work.

Conflicts of Interest: The authors declare no conflict of interest.

\section{Appendix A}

Table A1. Inhibition zones of bacteria strains growth (IZ) for paper disks impregnated with aqueous solutions * of dioxidine-based samples including metal nanoparticles ( ${ }^{*}$ dioxidine, $0.3 \mathrm{mass} \%$; $\mathrm{Ag}$, 0.0015 mass $\%$; Cu, 0.006 mass $\%)$.

\begin{tabular}{cccccc}
\hline $\begin{array}{c}\text { Bacterial } \\
\text { Strain }\end{array}$ & $\mathbf{I Z}, \mathbf{A g}, \mathbf{m m}$ & $\mathbf{I Z}, \mathbf{C u}, \mathbf{m m}$ & $\begin{array}{c}\text { IZ, Dioxidine, } \\
\mathbf{m m}\end{array}$ & $\begin{array}{c}\mathbf{I Z}, \mathbf{A g} / \text { dioxidine, } \\
\mathbf{~ m m}\end{array}$ & $\begin{array}{c}\mathbf{I Z}, \mathbf{C u} / \text { Dioxidine, } \\
\mathbf{m m}\end{array}$ \\
\hline E. coli 2 & 0 & 0 & $26.2 \pm 1.2$ & $36.7 \pm 0.6$ & $32.1 \pm 1.2$ \\
S. aureus 44 & 0 & 0 & $30.3 \pm 0.6$ & $37.1 \pm 0.6$ & $33.3 \pm 1.2$ \\
\hline
\end{tabular}


Table A2. Inhibition zones (IZ) of bacteria strains growth for biopolymer matrices impregnated with individual antibacterial drugs, metal nanoparticles, and their hybrid nanocomposites.

\begin{tabular}{|c|c|c|c|}
\hline Biopolymer Matrix & $\begin{array}{l}\text { Components Included in the } \\
\text { Hybrid Nanoform }\end{array}$ & E. $\operatorname{col} 52, \mathrm{IZ}, \mathrm{mm}$ & S. aureus $144, \mathrm{IZ}, \mathrm{mm}$ \\
\hline \multirow{8}{*}{ Ca-Alginate } & $\mathrm{Ag}$ & $10.0 \pm 0.6$ & 0 \\
\hline & $\mathrm{Cu}$ & 0 & 0 \\
\hline & Dioxidine & $20.0 \pm 0.6$ & $17 \pm 0.6$ \\
\hline & Dioxidine Ag & $23.0 \pm 0.8$ & $32 \pm 0.8$ \\
\hline & Dioxidine $\mathrm{Cu}$ & $22.1 \pm 1.2$ & $23 \pm 0.6$ \\
\hline & Gentamicin sulfate & $23.0 \pm 0.6$ & $18 \pm 0.6$ \\
\hline & Gentamicin sulfate Ag & $28 \pm 0.6$ & $21 \pm 0.6$ \\
\hline & Gentamicin sulfate $\mathrm{Cu}$ & $26 \pm 0.6$ & $19 \pm 0.8$ \\
\hline \multirow{8}{*}{ Gelatin } & $\mathrm{Ag}$ & $4 \pm 1.2$ & 0 \\
\hline & $\mathrm{Cu}$ & 0 & 0 \\
\hline & Dioxidine & $35 \pm 0.6$ & $10 \pm 0.6$ \\
\hline & Dioxidine Ag & $38 \pm 1.2$ & $15 \pm 0.6$ \\
\hline & Dioxidine $\mathrm{Cu}$ & $37 \pm 1.2$ & $14 \pm 0.6$ \\
\hline & Gentamicin sulfate & $32 \pm 0.6$ & $21 \pm 0.6$ \\
\hline & Gentamicin sulfate Ag & $34 \pm 1.2$ & $24 \pm 0.6$ \\
\hline & Gentamicin sulfate $\mathrm{Cu}$ & $36 \pm 0.6$ & $24 \pm 1.2$ \\
\hline \multirow{8}{*}{ Chitosan } & $\mathrm{Ag}$ & $7 \pm 1.0$ & $6.6 \pm 0.5$ \\
\hline & $\mathrm{Cu}$ & 0 & 0 \\
\hline & Dioxidine & $33.2 \pm 1.6$ & $11.5 \pm 2.5$ \\
\hline & Dioxidine Ag & $23.4 \pm 1.2$ & $7.5 \pm 0.6$ \\
\hline & Dioxidine $\mathrm{Cu}$ & $22.0 \pm 1.2$ & $6.5 \pm 0.5$ \\
\hline & Gentamicin sulfate & $29.0 \pm 1.0$ & $24.0 \pm 0.2$ \\
\hline & Gentamicin sulfate Ag & $28.3 \pm 1.4$ & $23.0 \pm 1.3$ \\
\hline & Gentamicin sulfate $\mathrm{Cu}$ & $28.3 \pm 0.8$ & $22.5 \pm 0.5$ \\
\hline
\end{tabular}

Table A3. Inhibition zones (IZ) of bacteria strains growth for paper disks impregnated with aqueous solutions ${ }^{* *}$ of samples based on gentamicin sulfate (** gentamicin sulfate, 0.3 mass $\%$; Ag, 0.0015 mass $\%$; $\mathrm{Cu}, 0.006$ mass $\%)$.

\begin{tabular}{cccccc}
\hline $\begin{array}{c}\text { Bacterial } \\
\text { Strain }\end{array}$ & IZ, Ag, $\mathbf{m m}$ & IZ, Cu, $\mathbf{m m}$ & $\begin{array}{c}\mathbf{I Z ,} \\
\text { Gentamicin } \\
\text { Sulfate, } \mathbf{m m}\end{array}$ & $\begin{array}{c}\mathbf{I Z ,} \\
\text { Ag/Gentamicin } \\
\text { Sulfate, } \mathbf{m m}\end{array}$ & $\begin{array}{c}\mathbf{I Z ,} \text { Cu/Gentamicin } \\
\text { Sulfate, mm }\end{array}$ \\
\hline E. coli 52 & 0 & 0 & $33.8 \pm 0.8$ & $36.5 \pm 0.6$ & $35.0 \pm 0.8$ \\
S. aureus 144 & 0 & 0 & $18.0 \pm 0.6$ & $21.1 \pm 0.6$ & $20.2 \pm 0.6$ \\
\hline
\end{tabular}

\section{References}

1. Gupta, A.; Saleh, N.M.; Das, R.; Landis, R.F.; Bigdeli, A.; Motamedchaboki, K.; Campos, A.R.; Pomeroy, K.; Mahmoudi, M.; Rotello, V.M. Synergistic antimicrobial therapy using nanoparticles and antibiotics for the treatment of multidrug-resistant bacterial infection. Nano Futures 2017, 1, 015004. [CrossRef]

2. Li, P.; Li, J.; Wu, C.; Wu, Q. Synergistic antibacterial effects of $\beta$-lactam antibiotic combined with silver nanoparticles. Nanotechnology 2005, 16, 1912-1917. [CrossRef]

3. Dong, X.; Awak, M.Al.; Tomlinson, N.; Tang, Y.; Sun, Y.-P.; Yang, L. Antibacterial effects of carbon dots in combination with other antimicrobial reagents. PLoS ONE 2017, 12, e0185324. [CrossRef] [PubMed]

4. Mitran, R.A.; Băjenaru, L.; Moisescu, M.G. Controlling drug release from mesoporous silica through an amorphous, nanoconfined 1-tetradecanol layer. Eur. J. Pharm. Biopharm. 2018, 127, 318-325. [CrossRef]

5. Ding, C.; Li, Z. A review of drug release mechanisms from nanocarrier systems. Mater. Sci. Eng. C Mater. Biol. Appl. 2017, 76, 1440-1453. [CrossRef]

6. Sami, A.J.; Khalid, M.; Jamil, T.; Aftab, S.; Mangat, S.A.; Shakoori, A.R.; Iqbal, S. Formulation of Novel Chitosan Guargum based Hydrogels for Sustained Drug Release of Paracetamol. Int. J. Biol. Macromol. 2018, 108, 324-332. [CrossRef] 
7. Ito, T.; Takami, T.; Uchida, Y.; Murakami, Y. Chitosan gel sheet containing drug carriers with controllable drug-release properties. Colloids Surf. B Biointerfaces 2018, 163, 257-265. [CrossRef]

8. Kamaly, N.; Yameen, B.; Wu, J.; Farokhzad, O.C. Degradable Controlled-Release Polymers and Polymeric Nanoparticles: Mechanisms of Controlling Drug Release. Chem. Rev. 2016, 116, 2602-2663. [CrossRef]

9. Li, J.; Mooney, D.J. Designing hydrogels for controlled drug delivery. Nature Rev. Mater. 2016, 1. [CrossRef]

10. Vicent, M.J.; Duncan, R. Polymer conjugates: Nanosized medicines for treating cancer. Trends Biotechnol. 2006, 24, 39-47. [CrossRef]

11. Hasnain, M.S.; Nayak, A.K.; Singh, M.; Tabish, M.; Ara, J. Alginate-based bipolymeric-nanobioceramic composite matrices for sustained drug release. Int. J. Biol. Macromol. 2016, 83, 71-77. [CrossRef] [PubMed]

12. Jalababu, R.; Veni, S.; Reddy, K.V.N.S. Synthesis and characterization of dual responsive sodium alginate-g-acryloyl phenylalanine-poly $\mathrm{N}$-isopropyl acrylamide smart hydrogels for the controlled release of anticancer drug. J. Drug Deliv. Sci. Technol. 2018, 44, 190-204. [CrossRef]

13. Bini, R.A.; Silva, M.F.; Varanda, L.C.; da Silva, M.A.; Dreiss, C.A. Soft nanocomposites of gelatin and poly (3-hydroxybutyrate) nanoparticles for dual drug release. Colloids Surf. B Biointerfaces 2017, 157, 191-198. [CrossRef] [PubMed]

14. Talebian, A.; Mansourian, A. Release of Vancomycin from electrospun gelatin/chitosan nanofibers. Mater. Today Proc. 2017, 4, 7065-7069. [CrossRef]

15. Saikova, S.V.; Vorob'ev, S.A.; Nikolaeva, R.B.; Mikhlin, Y.L. Conditions for the formation of copper nanoparticles by reduction of copper (II) ions with hydrazine hydrate solutions. Russ. J. Gen. Chem. 2010, 80, 1122-1127. [CrossRef]

16. Vernaya, O.I.; Khvatov, D.I.; Nuzhdina, A.V.; Fedorov, V.V.; Shabatin, V.P.; Semenov, A.M.; Shabatina, T.I. $\mathrm{Cu}$ /Dioxidine Hybrid Nanocomposites: Cryochemical Synthesis. Mosc. Univ. Chem. Bull. 2016, 71, 224-226.

17. Vernaya, O.I.; Shabatin, V.P.; Semenov, A.M.; Shabatina, T.I. Cryochemical Synthesis and Antibacterial Activity of a Hybrid Composition Based on Ag Nanoparticles and Dioxidine. Mosc. Univ. Chem. Bull. 2017, 72, 6-9. [CrossRef]

18. Zvukova, N.D.; Klimova, T.P.; Ivanov, R.V.; Ryabev, A.N.; Tsiskarashvili, A.V.; Lozinsky, V.I. Cryostructuring of polymeric systems. 52. Properties, microstructure and an example of a potential biomedical use of the wide-pore alginate cryostructurastes. Gels 2019, 5, 25. [CrossRef]

19. Sazhnev, N.A.; Drozdova, M.G.; Rodionov, I.A.; Kil'deeva, N.R.; Balabanova, T.V.; Markvicheva, E.A.; Lozinsky, V.I. Preparation of chitosan cryostructurates with controlled porous morphology and their use as 3D-scaffolds for culturing of animal cells. Appl. Biochem. Microbiol. 2018, 54, 459-467. [CrossRef]

20. Lozinsky, V.I.; Kulakova, V.K.; Ivanov, R.V.; Petrenko, A.Y.; Rogulska, O.Y.; Petrenko, Y.A. Cryostructuring of polymer systems. 47. Preparation of wide porous gelatin-based cryostructurates in sterilizing organic media and assessment of the suitability of thus formed matrices as spongy scaffolds for 3D cell culturing. E-Polymers 2018, 18, 175-186. [CrossRef]

21. Shabatina, T.I.; Vernaya, O.I.; Shabatin, V.P.; Evseeva, I.V.; Melnikov, M.Y.; Fitch, A.N.; Chernyshev, V.V. Cryochemically Obtained Nanoforms of Antimicrobial Drug Substance Dioxidine and Their Physico-chemical and Structural Properties. Crystals 2018, 8, 298. [CrossRef]

22. Vernaya, O.I.; Shabatin, V.P.; Shabatina, T.I.; Khvatov, D.I.; Semenov, A.M.; Yudina, T.P.; Danilov, V.S. Cryochemical modification, activity, and toxicity of dioxidine. Russ. J. Phys. Chem. A 2017, 91, $229-232$. [CrossRef]

23. Vernaya, O.I.; Shabatin, V.P.; Semenov, A.M.; Shabatina, T.I. Obtaining ultradispersed dioxidine powder modified. Mosc. Univ. Chem. Bull. 2016, 71, 291-298. [CrossRef]

24. Rosenkrantz, B.E.; Greco, J.R.; Hoogerheide, J.G.; Oden, E.M. Gentamicin sulfate. Anal. Profiles Drug Subst. 1981, 9, 295-340.

25. Deubner, R.; Schollmayer, C.; Wienen, F.; Holzgrabe, U. Assignment of the major and minor components of gentamicin for evaluation of batches. Magn. Reson. Chem. 2003, 41, 589-598. [CrossRef]

(C) 2019 by the authors. Licensee MDPI, Basel, Switzerland. This article is an open access article distributed under the terms and conditions of the Creative Commons Attribution (CC BY) license (http://creativecommons.org/licenses/by/4.0/). 